\title{
AMCP Partnership Forum: What's Next for Specialty Medication Benefit Design and Reimbursement
}

\section{SUMMARY}

Rising specialty drug costs present a challenge for patients and payers. High-cost products, such as gene therapies or immunotherapies, can significantly affect the budget of a payer that does not have the ability to spread risk across a large population. Stakeholders are considering new reimbursement and benefit designs for specialty medications to improve efficiencies and better manage costs. The potential effect of changes to specialty medication benefit designs and reimbursement systems on patient care, access to medications, and the overall health care system are important considerations when assessing the benefits and challenges associated with reform proposals.

Options to better manage the affordability of specialty medications are needed to ensure that patients can continue to access medications, while allowing payers to remain good stewards of health care dollars and supporting marketplace competition and incentives to stimulate innovation. New benefit designs that address these needs, while also supporting marketplace competition and providing incentives that stimulate innovation, have been considered. To explore options, AMCP convened a multidisciplinary stakeholder forum on December 10-11, 2019, in Alexandria, VA. Health care leaders representing academia, health plans, integrated delivery systems, industry leaders, pharmaceutical manufacturers, pharmacy benefit managers, employers, federal government agencies, national health care provider organizations, and patient advocacy organizations participated in the forum.

The forum was designed for stakeholders to discuss strategies for the following: (a) reduce costs for beneficiaries while maintaining or improving access to prescription drugs; (b) support marketplace competition and incentives for biopharmaceutical innovation; (c) minimize physicians' financial risk associated with managing drug inventories; (d) remove adverse reimbursement incentives for prescribing higher priced drugs; (e) consider the cost-effectiveness of treatments and services across the health care continuum; and (f) support quality measurement and program evaluation metrics.

Recommendations emerging from the forum included creation of novel payment models for the most expensive therapies that allow for larger risk pools, while maintaining the sustainability of the reinsurance market remains. Simplification and standardization were cited as goals for system reform and technological innovations that allow health care providers to view cost-effectiveness information at the point of prescribing, combined with value-based contracting were also recommended. Finally, ensuring that plans remain patient-centric and are designed to address patient needs holistically was stressed as an important goal.

J Manag Care Spec Pharm. 2020;26(10):1206-13

Copyright $\odot 2020$, Academy of Managed Care Pharmacy. All rights reserved.
C osts associated with specialty medications have drawn scrutiny as the percentage of overall prescription spending on these medications grew from $34.4 \%$ of the prescription market in 2013 to $49.5 \%$ of the prescription market in 2018. ${ }^{1}$ The share of prescription drug spending on specialty products is expected to continue to grow because of a robust development pipeline that contains numerous promising innovative therapies that are expected to be associated with higher costs.

In the United States, federal efforts are underway to address prescription drug spending. For example, in May 2018, the Centers for Medicare \& Medicaid Services (CMS) released a proposed rule to lower drug prices and reduce out-of-pocket costs, which focused on improving competition, increasing negotiation, lowering list prices, and reducing out-of-pocket costs. ${ }^{2}$ AMCP submitted comments on this proposed rule that encouraged CMS to allow health plans more flexibility in managing Medicare Part B and Part D drugs. ${ }^{3}$ Additionally, the Prescription Drug Pricing Reduction Act of 2019 is a bipartisan bill that is currently under consideration by Congress. ${ }^{4}$ Key issues addressed in the aforementioned congressional proposals include rebates based on inflation, direct price negotiations, and Medicare Part D redesign.

AMCP convened a partnership forum December 10-11, 2019, in Alexandria, VA, to explore existing issues with specialty medication benefits and payment systems with the intent of developing recommendations for improving these systems. Table 1 includes a listing of selected readings regarding the health care system and policy reform proposals that were shared with meeting participants or referred to during the meeting.

Evaluating Existing Specialty Medication Benefits and Reimbursement Systems

To better inform perspectives to address prescription drug pricing, participants reviewed existing gaps and identified strengths and weaknesses of current specialty medication reimbursement systems in the United States (Table 2). Participants identified several existing strengths and areas for innovation but recognized that weaknesses can impede some of these efforts.

\section{Access to Care Through Innovative Benefit Design}

Participants observed that, in the United States, patients generally have adequate access to care, supported in part by laws, accreditation standards, and patient assistance programs. However, access is not universal and is often lacking for uninsured patients. 
Organization/Entity

USC-Brookings Schaeffer on Health Policy

The Commonwealth Fund

Speaker of the House

Congressional Budget Office

Kaiser Family Foundation Medication Proceedings Institute for Clinical and Economic Review

Senator Bill Cassidy, MD

\section{Resource}

Alder L, Ginsburg PB, Lieberman, SM. Understanding the bipartisan Senate Finance prescription drug reform package. Available at: https://www.brookings.edu/blog/usc-brookings-schaeffer-on-health-policy/2019/10/03/understanding-the-bipartisan-senate-finance-prescription-drug-reform-package/. Accessed July 29, 2020.

Wynne B, Llamas A. New legislation to control drug prices: how do House and Senate bills compare? Available at: https:// www.commonwealthfund.org/blog/2019/new-legislation-control-drug-prices-how-do-house-and-senate-bills-compare. Accessed July 29, 2020.

H.R. 3, the Lower Prescription Drug Costs Now Act. For the People. October 2, 2019. Available at: https://www.speaker.gov/ sites/speaker.house.gov/files/HR3\%20Backgrounder\%2010.2.19.pdf. Accessed July 29, 2020.

Congressional Budget Office. Effects of drug price negotiation stemming from Title 1 of H.R. 3, the Lower Drug Costs Now Act of 2019, on spending and revenues related to Part D of Medicare. October 11, 2019. Available at: https://www.cbo.gov/ system/files/2019-10/hr3ltr.pdf. Accessed July 29, 2020.

Kaiser Family Foundation. Out-of-pocket cost burden for specialty drugs in Medicare Part D in 2019. Issue Brief. February 2019. Available at: http://files.kff.org/attachment/Issue-Brief-the-Out-of-Pocket-Cost-Burden-for-Specialty-Drugs-in-MedicarePart-D-in-2019. Accessed July 29, 2020.

AMCP. Advanced notice of proposed rulemaking for Medicare program; International Pricing Index Model for Medicare Part B drugs. October 30, 2018. Available at: https://www.amcp.org/sites/default/files/2019-02/AMCP\%20Summary\%20 \%E2\%80\%93\%20Advanced\%20Notice\%20of\%20Proposed\%20Rulemaking\%20for\%20Medicare\%20Program\%3B\%20 International\%20Pricing\%20Index\%20Model\%20for\%20Medicare\%20Part\%20B\%20Drugs.pdf. Accessed July 29, 2020.

AMCP Partnership Forum: Designing benefits and payment models for innovative high-investment medications. J Manag Care Spec Pharm. 2019;25(2):156-62. Available at: https://www.jmcp.org/doi/full/10.18553/jmcp.2019.25.2.156.

Institute for Clinical and Economic Review. Value, access, and incentives for innovation: policy perspectives on alternative models for pharmaceutical rebates. March 2019. Available at: https://icer-review.org/wp-content/uploads/2019/03/March2019-ICER-OHE-White-Paper-on-Rebates-Final.pdf. Accessed July 29, 2020

Cassidy B. Ideas to make health care affordable again. May 2018. Available at: https://www.cassidy.senate.gov/imo/media/doc/ Dr\%20Bill\%20Cassidy\%20-\%20Make\%20Health\%20Care\%20Affordable\%20Again.pdf. Accessed July 29, 2020.
Health care benefits in the United States are highly regulated, although there is some variability in regulations based on the lines of business (e.g., Medicare vs. commercial), noted participants. For example, Medicare and Medicaid must cover products based on information in certain compendia. However, rare conditions and off-label uses may not be addressed by these compendia, which can influence access for affected patients. Over time, consistencies in regulations sometimes emerge because accreditation requirements for commercial insurers often follow requirements for governmental payers.

Participants stressed that, ideally, medical and pharmacy benefit designs are patient-centric and address patient health needs holistically. They called for benefit designs that focus on total cost of care and overall health improvements and address social determinants of health.

Participants discussed that patient out-of-pocket costs pose another challenge within the current system. When patients are responsible for paying for a percentage of the cost of a product (i.e., a coinsurance rather than a fixed-price copay), the cost can become prohibitive for high-cost therapies. In some cases, patients may reach an out-of-pocket maximum. However, out-of-pocket maximums can dramatically affect the household budgets for many patients. Manufacturers' patient assistance programs are available to help address some of these gaps. However, they may not be accessible to all patients (e.g., Medicare beneficiaries).

\section{Utilization Management Strategies}

Participants noted that there are many effective utilization management strategies within the pharmacy benefit, such as formulary controls, that could be replicated within the medical benefit. They also called for integrating management strategies across benefits to support the use of cost-effective strategies. They noted that site of care can have an effect on the cost of a medication and corresponding delivery fees (e.g., infusions) and encouraged the use of management tools that support the use of the most cost-effective sites-of-care delivery. Further, participants observed that prior authorization programs are often used to help ensure that medications are prescribed to the most appropriate patients. However, the administrative burdens associated with these programs and defining appropriate patient populations are important considerations.

Generic small molecule drugs and biosimilar product approvals have the potential to increase competition by offering lower-cost alternatives to specialty medications when patents expire. These products are increasingly gaining regulatory approval. To date, market share growth for biosimilars has been incremental; increased biosimilar adoption could help address costs. Participants indicated that, in general, the role of utilization management programs to facilitate biosimilar uptake is 


\begin{tabular}{|c|c|}
\hline Issue & Example \\
\hline \multicolumn{2}{|l|}{ Strengths } \\
\hline Access to care & Patients in the United States have robust access to innovative therapies and curative technologies. \\
\hline Accreditation standards & NCQA and URAC have requirements that support patient access to care. \\
\hline $\begin{array}{l}\text { Patient assistance programs and } \\
\text { out-of-pocket maximums }\end{array}$ & Patient costs can be limited by these programs and provisions. \\
\hline Competition & For some therapeutic areas, multiple specialty treatments, including generics and biosimilars, can help control costs. \\
\hline Pharmacy claims management & $\begin{array}{l}\text { Pharmacy benefits currently have the capability to provide clear and transparent real-time information on whether a } \\
\text { product is covered and the cost to the patient. }\end{array}$ \\
\hline Data integration & Innovation is allowing for improved data integration in and across some health care systems. \\
\hline Role of pharmacists & Medication expertise and access to electronic medical records can support high-quality care. \\
\hline Value-based contracts & These contracts support innovation in the delivery of cost-effective care and tracking of costs and outcomes. \\
\hline Automated prior authorization & Use of technology to streamline processes (e.g., ePA) is reducing the administrative burden. \\
\hline Shared savings models & Allowing providers to receive incentives for controlling cost of care can support the selection of cost-effective therapies. \\
\hline $\begin{array}{l}\text { Catastrophic coverage/ } \\
\text { reinsurance }\end{array}$ & $\begin{array}{l}\text { These types of insurance plans allow risk to be pooled across a larger population; however, gaps remain for some } \\
\text { patients. }\end{array}$ \\
\hline Innovation & The current health care system provides strong incentives for biopharmaceutical and digital therapeutic innovation. \\
\hline Information sharing & $\begin{array}{l}\text { Pre-approval information exchange allows for payers to better prepare for the entry of a new product before it receives } \\
\text { regulatory approval. }\end{array}$ \\
\hline \multicolumn{2}{|l|}{ Weaknesses } \\
\hline Medical claims management & Real-time data about coverage and cost of care are generally not available. \\
\hline Lack of standardization & Substantial plan-to-plan variability in coverage, requirements, and costs exists and complicates reform areas. \\
\hline Patient costs & $\begin{array}{l}\text { Cost sharing is disproportionate across disease states. Coinsurance requirements can become expensive. } \\
\text { Patients often are uninformed about their coverage. } \\
\text { Annual deductibles can be expensive for patients. }\end{array}$ \\
\hline Sites of care & $\begin{array}{l}\text { Variable medication and administration costs for the system and patients across sites of care may create misaligned } \\
\text { incentives. } \\
\text { Inconsistent sites of care may increase administrative burdens and complicate patients' abilities to understand their } \\
\text { benefits and self-direct care. }\end{array}$ \\
\hline Administrative burdens & $\begin{array}{l}\text { Utilization management programs can require substantial uncompensated staff and provider time and can affect patient } \\
\text { access. } \\
\text { Lack of therapeutic interchange for biologics and biosimilars increases the clinic medication stocking systems and } \\
\text { introduces complexity for clinic-administered medications. }\end{array}$ \\
\hline Fragmentation of care & $\begin{array}{l}\text { Separation of benefits (e.g., pharmacy and medical) impedes assessments of outcomes and fails to incentivize } \\
\text { interventions that reduce the total cost of care. }\end{array}$ \\
\hline Short-term benefit designs & $\begin{array}{l}\text { Plans are often focused on the next quarter or plan year rather than taking a longer-term view. This framework can be } \\
\text { of particular concern when considering cost of curative therapies. } \\
\text { Plans have difficulty in predicting how to budget for newly approved high-investment medications }\end{array}$ \\
\hline Legacy pricing schemes & $\begin{array}{l}\text { Legacy pricing schemes may drive misaligned incentives. For example, ASP }+6 \% \text { system results in higher prescriber } \\
\text { compensation for more expensive medications. }\end{array}$ \\
\hline $\begin{array}{l}\text { Direct and indirect remuneration } \\
\text { (DIR) fees }\end{array}$ & $\begin{array}{l}\text { Rebates, administrative fees, and adjustments based on performance metrics are often not transparent and can } \\
\text { complicate assessments of value. }\end{array}$ \\
\hline Barriers to value-based care & Lack of transparency and data interoperability make it difficult to track costs. \\
\hline $\begin{array}{l}\text { Barriers to value-based contracts } \\
\text { for pharmaceuticals }\end{array}$ & $\begin{array}{l}\text { Legal and regulatory restrictions (e.g., Anti-Kickback Statute and Medicaid Best Price) create barriers by restricting } \\
\text { many potential contract terms. }\end{array}$ \\
\hline $\begin{array}{l}\text { Data needs for orphan drug } \\
\text { approvals and conditions }\end{array}$ & Sufficient data to properly inform treatment and coverage decisions for rare conditions may be lacking. \\
\hline
\end{tabular}

ASP = average sales price; NCQA = National Commission on Quality Assurance; URAC = Utilization Review Accreditation Commission.

well supported, since increased competition has the potential to help improve medication affordability. However, participants indicated that regulatory requirements to cover specific products/therapeutic classes constrain payers' negotiation power. Furthermore, some providers are burdened to stock multiple biosimilars for a single innovator product to support different payer contracts. If there were therapeutic interchangeability for biologics and biosimilars, it could decrease administrative burdens and overhead costs related to storage and inventory management. 


\section{Recommendations for Improving Specialty Benefit Design and Reimbursement}

Participants evaluated several factors that can influence specialty medication payment systems (Table 3 ) and identified opportunities for improvement. Themes that were discussed by participants included pharmaceutical contracting, insurance design, technology innovation, longitudinal patient databases, early information sharing, and legislative and regulatory issues.

\section{Pharmaceutical Contracting}

Participants observed that manufacturer rebates influence which medications patients receive. Furthermore, considering which stakeholders receive the savings that are generated through rebates is an emerging policy issue. Suggestions shared by participants included providing a significant proportion of the rebate savings to patients, instead of providers, pharmacy benefit managers, or payers at the point of sale. Furthermore, another consideration is that the savings that payers negotiate can be used to reduce premiums for all patients or to invest in other health care services. Participants noted that rebates increase administrative overhead and favored simplified approaches to reducing overall costs (such as a lower list price or percentage discount up front), which would also support making drug pricing more transparent.

The effect of prescription drugs on the total cost of care is an important consideration when assessing their value. Valuebased agreements between manufacturers and payers have emerged as one strategy to better align specialty medication reimbursement to its demonstrated real-world value. Valuebased agreements between payers and providers can be used to incentivize prescribers to provide cost-effective care. However, these agreements can be complex to implement and can present operational challenges, including data management, interoperability, and meeting legal and regulatory requirements, such as the Anti-Kickback Statute and the Medicaid Best Price. In general, entities that are accountable for the total cost of care are more interested in implementing value-based arrangements.

\section{Site-of-Care Delivery}

The site-of-care delivery was identified by participants as a potential misaligned incentive in the insurance benefit design. For example, the price of an infused medication can vary substantially depending on the location at which it is administered (e.g., outpatient infusion center, a physician's office, stand-alone infusion center, or home infusion). System costs and patient out-of-pocket costs vary based on the site of care. Participants recommended that benefits and system networks be designed so that the most appropriate site of care is also the most cost-effective for the patient and the payer; however, specific recommendations on how to accomplish this were not discussed.

\section{Insurance Design}

Participants identified several challenges associated with insurance designs. For example, most health care benefit plans cover patients based on a 12-month cycle. Health care savings generated by curative therapies (e.g., gene therapy) can be expected to persist much longer, perhaps a lifetime, resulting in savings many years later. Because most patients are not likely to remain with the same payer for the entire period of a treatment's benefit, the cost-effectiveness benefit of the investment in curative therapies is often distributed across multiple payers. Participants discussed the opportunities around restructuring 12-month cycle benefit plans to longer durations (e.g., 5 to 10 years) for specific high-investment/high-value interventions, such as gene therapy.

Expanded use of value-based insurance design and alternative payment models was identified as a strategy that could be leveraged to address an array of specialty medication challenges, including patient adherence and social determinants of health. Building delivery-system networks and benefits to direct care to centers of excellence was cited as a model that addresses a complex array of patient needs to support comprehensive patient care. Participants also recommended leveraging lessons learned from care models used for allocating scarce lifesaving treatments (e.g., organ transplants) and considering innovative coverage models for specific treatments and technologies.

\section{Reinsurance and Annuities}

Participants identified reinsurance services that allow smaller plans to manage high costs by spreading risk across larger populations as an important strategy for helping manage risk associated with specialty medication costs. However, they observed that these plans may also limit coverage for specific patients or patient populations with certain conditions. To be viable, they would need to ensure appropriate access to care. Participants discussed the potential role of government-funded high-risk pools that do not exclude specific sets of patients (such as those with diagnoses warranting gene therapy). Government-backed reinsurance programs would have larger risk pools and be better incentivized to invest in population health interventions and curative therapies.

Annuities, which amortize cost over time, were also proposed as a payment model for high-cost therapies. However, participants generally were not in favor of these payment models because they can complicate the administration of current insurance models.

\section{Technology Innovation}

Participants acknowledged that several technological innovations are advancing specialty medication benefits but indicated that more work is needed. They cited barriers to data interoperability across various benefits and the hindering of comprehensive assessments by stakeholders and noted that prescribers 


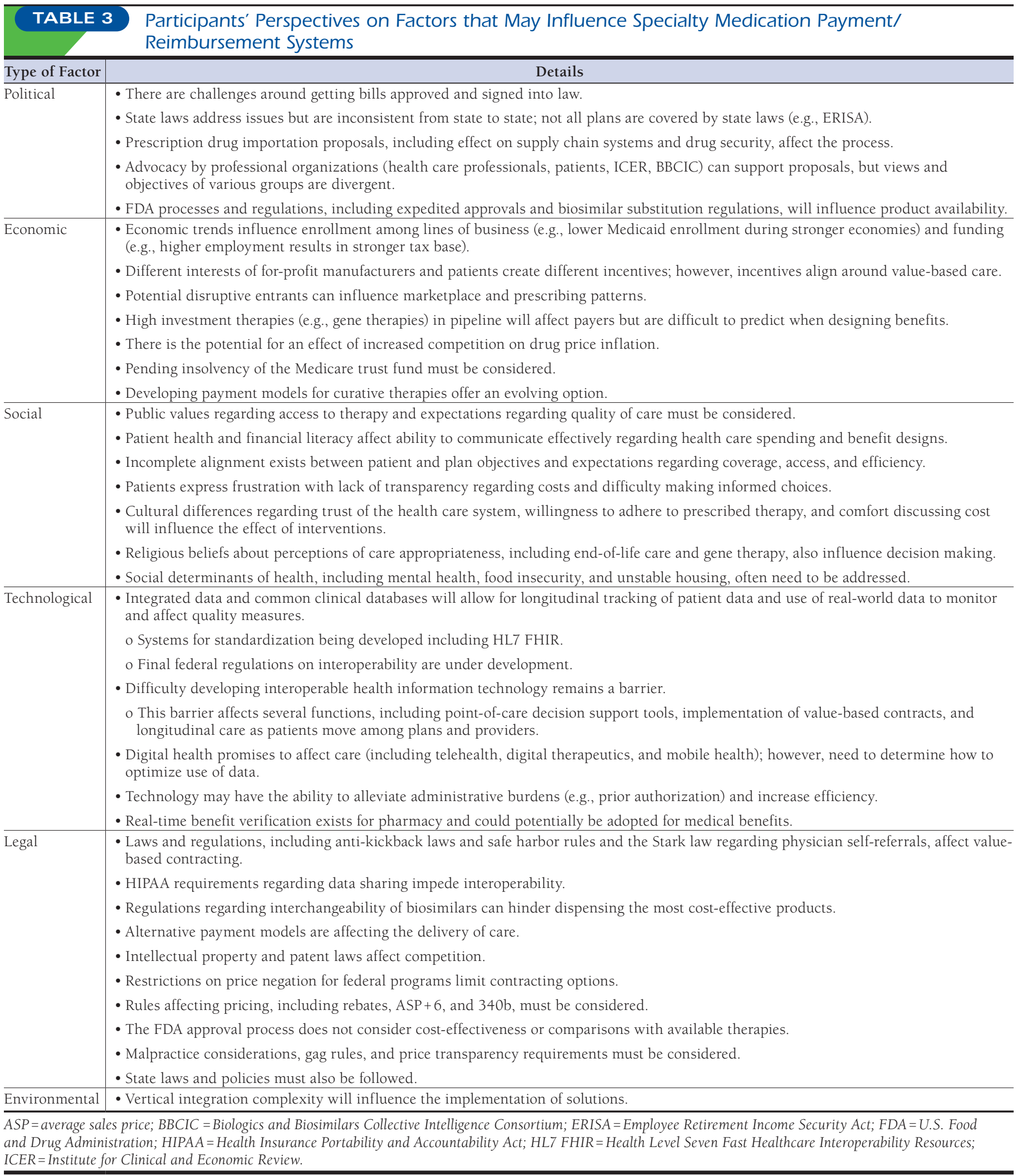


generally do not have access to the needed information at the point of prescribing. For example, although biosimilars have the potential to lower costs, a prescriber may not readily have access to information regarding which biosimilar is preferred in a patient's plan. Participants offered several recommendations for how to improve health information technology (HIT) to support effective reimbursement and payment for specialty drugs.

Real-time benefit tools at the point of prescribing and utilization management strategies used by the pharmacy benefit were highlighted as systems and processes that should be applied to the medical benefit. Participants identified that information technology processes need to be further developed, however, to support similar processes for medications covered under the medical benefit. Participants identified a need for integrated datasets that would allow for enhanced management programs across pharmacy and medical coverage, including utilization management, claims integration, and retrospective drug utilization review.

Participants noted that, in some cases, real-time benefit tools are available as an add-on service in an HIT system but that not all providers pay for the service or that it requires providers to navigate multiple processes in order to get the information needed for the specific patient. They called for these systems to be standardized and integrated within the workflow for providers so that information from all payers is readily available and accessible within the patient's record.

Participants cited low-cost digital innovations for remote patient monitoring to improve patient adherence and link patients to appropriate support services as an emerging tool that could be leveraged to improve the delivery of care. Participants observed that the expanded use of mobile health (mHealth) products and digital therapeutics creates large volumes of data that can enhance patient care with the understanding that the data needs to be presented to providers in a manner that is accessible and actionable.

\section{Longitudinal Patient Database and Data Integration}

Participants called for the creation of longitudinal databases that could track patients as they switch among providers and payers. Such a database would allow for more advanced assessments of patient needs, support care coordination and continuity of care, and would reduce administrative burdens and challenges associated with fragmented care. Integration of such data within a longitudinal database could enhance the availability and use of real-world evidence for the administration of value-based contracts.

Longitudinal databases could also support the development of systems that facilitate payments over time for certain highcost products. However, participants noted that issues regarding data interoperability, data ownership, and patient privacy would need to be addressed in order to effectively deploy such a centralized database.
Strategies that were suggested by participants to support better data integration include coordination across benefits and improved data interoperability. Participants recommended the adoption of pharmacy claims management practices by medical benefit systems to support pricing transparency and cost-effective decision making.

\section{Early Information Sharing}

Participants indicated that, although pre-approval information exchange can help payers prepare to quickly integrate new therapies into their formularies when they are approved, stakeholders are not fully optimizing the value of these communication channels. Participants called for greater communication among manufacturers and payers before product approvals and recommended the use of pre-approval dossiers to facilitate and streamline communication.

\section{Legislative and Regulatory Strategies}

Participants stressed the need for advocacy to address legal and regulatory barriers to improving the cost-effectiveness of care. In particular, they cited modernization of the Anti-Kickback Statute and Medicaid Best Price requirements as important to support wider use of value-based agreements. They also cited prescription drug reimbursement model changes as an opportunity to address challenges regarding direct and indirect remuneration (DIR) fees, including rebates, average sales price (ASP) $+6 \%$, and site-of-care provisions. Strategies that would control costs by supporting increased competition, such as by increasing access to biosimilars through expanded interchangability, were proposed.

Considerations regarding the benefits and drawbacks of government price negotiation were discussed by participants. They encouraged the creation of policies that would help manage costs associated with prescription products. Some recommended the implementation of policies that increase competition. However, there are no therapeutic equivalents for certain high-cost interventions and, therefore, no opportunities for negotiating their prices based on market competition. Attempts to enhance the ability of the government to negotiate prices were also discussed. Some participants cautioned against the implementation of government price controls over concerns for the potential to reduce patient access to innovative therapies.

Many participants advocated for market-based solutions with the caveat that there would be a need for greater transparency and ability to compare actual prices for effective solutions. Some noted that the government already does negotiate price through the Department of Veterans Affairs and Medicare Part D prescription drug plans and that allowing for broader negotiation would leverage economies of scale and reduce waste. Allowing the U.S. Food and Drug Administration to evaluate the cost-effectiveness of new treatments and using 
information from value assessment frameworks could increase incentives to better manage costs and were also suggested as options.

Participants observed that any system changes will be associated with benefits and drawbacks that may not be equally shared among stakeholders. To address this reality, participants recommended policies that support incremental change. At the same time, they recognized that some changes need to occur concurrently. For example, the elimination of ASP+6 will need to be paired with a model that compensates providers for delivering medication-related services.

\section{Looking to the Future}

New payment models for the most expensive therapies that allow for larger risk pools and avoid exclusion of certain patients, while also ensuring that the reinsurance market remains sustainable, emerged as a recommendation during the forum. Some participants suggested that gene therapies be covered through a separate pooled risk benefit, rather than through specialty pharmacy to avoid the effect on smaller payers. Some participants also suggested the creation of requirements regarding the coverage that should be provided through the reinsurance market similar to the essential health benefits requirements under the Affordable Care Act.

Simplification and standardization were cited as goals for system reform. Definitions for aspects of payment models, such as agreement among stakeholders on how cost is defined, were cited as needs for a simplified system that is based on value. Participants believed that a simplified system with more integration of benefits would help to ensure that payment formulas support value and prevent misaligned incentives.

Participants stressed that the role of a health care system is to improve health and remarked that systems should be designed to be patient-centric and improve outcomes for patients. This shift included the creation of benefit designs that address a wide range of patient needs, including psychosocial issues and social determinants of health and the delivery of supportive services to optimize patient outcomes. It also includes caring for the patient holistically over time with a focus on interventions that keep patients healthy rather than focusing on episodic or acute care. Incentivizing patients to adhere to recommended treatments and lowering out-of-pocket costs were also acknowledged as priorities. Engaging pharmacists and mid-level practitioners was cited as a cost-effective strategy for delivering these interventions. Integrated benefit designs that are accountable for total cost of care were recommended as important strategies for supporting holistic patient health.

Participants called for AMCP to continue to embrace its role as a convener of stakeholders and as an advocate for reforms. They cited AMCP's experience collaborating with a wide range of groups, including patient groups, payers, employers, manufacturers, and government representatives and ability to foster interdisciplinary collaborations. In addition, they called on AMCP to continue efforts to educate all stakeholders about issues affecting specialty drug reimbursement so that decision makers can be well informed about the potential effects of reforms.

Finally, participants called for AMCP to deliver education and resources that highlight best practices to share with stakeholders, including case studies of successful practices that support delivery of high-value care. Shared resources for clinical decision support were also cited as an important tool that could support cost-effective care. They also recognized a need for increased patient education around benefit designs and recommended that the AMCP Foundation pursue funding and partner with organizations to lead these initiatives. Participants also supported the idea of a respected entity developing a centralized longitudinal database for sharing patient data.

\section{Forum Participants}

POOJA BABBRAH, MBA, Senior Consultant, Point-of-Care Partners; LISA CASHMAN, PharmD, Director, Clinical Account Services, MedImpact Healthcare Systems; RICHARD DEMERS, RPh, MS, Chief Administrative Officer, Ambulatory Pharmacy Services, Penn Medicine; SARA DENO, PharmD, Managed Care Pharmacist; JULIE DITUCCI-REITER, PharmD, Clinical Policy and Programs, Steward Health Choice; CLAIRE DYBALA, PharmD, Senior Director, Account Medical Lead Team, Takeda; STEPHEN GEORGE, PharmD, MS, Milliman; ESTAY GREENE, PharmD, MBA, Vice President, Pharmacy Services, Blue Cross Blue Shield of North Carolina; DOROTHY HOFFMAN, Healthcare Innovation Center - Access Innovation Lead, Pfizer; DANIEL KENT, PharmD, CDE, Specialty Clinical Pharmacy Quality Coordinator, Kaiser Permanente of Washington; GRANT KNOWLES, PharmD, CSP, Vice President, Business Development E Industry Relations, Ardon Health; KOLLET KOULIANOS, MBA, Senior Director Payer Relations, National Hemophilia Foundation; LAUREN LIGGETT, Director, Strategic Market Access, Xcenda; GREG LOW, RPh, PhD, Director, Massachusetts General Physicians Organization's Pharmacy Quality and Utilization Program, Massachusetts General Hospital; GEORGE MAYZELL, MD, MBA, Principal, Empowered Healthcare; NATALIE MORRIS, JD, MPP, Head, U.S. Policy, AstraZeneca; VINCENT PACILEO, Director, Federal Affairs, Arthritis Foundation; YUSUF RASHID, RPh, Vice President, Pharmacy and Vendor Relations, Community Health Plan of Washington; CARLY RODRIGUEZ, PharmD, FAMCP, Pharmacy Director, Clinical Innovation, Moda Health; BRETT SAHLI, PharmD, Senior Director, Specialty Pharmacy Programs and Strategy, Prime Therapeutics; MITCHEL SELEZNICK, MD, MPH, MBA, FACP, Medical Director, CarePlus Health Plans Pharmacy; LYSSA SIFFRING, Director, Specialty Brand Payer and Access Marketing, GSK; IRINA SMITH, PharmD, CSP, Specialty Pharmacist - Policies, CareSource; JASON SPANGLER, MD, MPH, FACPM, Executive Director, Amgen; DEBBIE STERN, RPh, President, Rxperts Consulting; DANIEL TOMASZEWSKI, PharmD, PhD, Assistant Professor, Managed Care Consultant, Chapman University School of Pharmacy; LAURA TOPOR, 


\section{Forum Participants (continued)}

President, Granada Health; HAI TRAN, PharmD, BCPS, Associate Director, Drug Use Policy, Cedars Sinai Medical Center; KATIE VERB, Director, Policy E Research, PhRMA; and NEIL WARNOCK, MD, Deputy Director, Medical Affairs - Market Access, Bayer.

CORRESPONDENCE: Cynthia Reilly, MS, BSPharm, Chief Operating Officer, AMCP, 675 N. Washington St., Alexandria, VA 22314.Email: creilly@amcp.org.

\section{DISCLOSURES}

This partnership forum was sponsored by Amgen, AstraZeneca, Bayer, GSK, Merck, Pfizer, PhRMA, Takeda, and Xcenda. These proceedings were prepared as a summary of the forum to represent common themes; they are not necessarily endorsed by all attendees nor should they be construed as reflecting group consensus.

\section{ACKNOWLEDGMENTS}

The AMCP Partnership Forum "What's Next for Specialty Medication Benefit Design and Reimbursement" was moderated by Susan Winckler. These proceedings were written by Judy Crespi Lofton, Medical Writer and Consultant, JCL Communications.

\section{REFERENCES}

1. IQVIA. Medicine use and spending in the U.S. A review of 2018 and outlook to 2023. May 9, 2019. Available at: https://www.iqvia.com/insights/ the-iqvia-institute/reports/medicine-use-and-spending-in-the-us-a-reviewof-2018-and-outlook-to-2023. Accessed July 28, 2020.

2. Centers for Medicare \& Medicaid Services. Modernizing Part D and Medicare Advantage to Lower Drug Prices and Reduce Out-Of-Pocket Expenses. Final rule. 84 FR 23832. Available at: https://www.federalregister. gov/documents/2019/05/23/2019-10521/modernizing-part-d-and-medicareadvantage-to-lower-drug-prices-and-reduce-out-of-pocket-expenses. Accessed July 28, 2020

3. Academy of Managed Care Pharmacy. Re: Modernizing Part D and Medicare Advantage to Lower Drug Prices and Reduce Out-of-Pocket Expenses [CMS-4180-P]. January 25, 2019. Available at: https://www.amcp.org/sites/ default/files/2019-03/AMCP\%20Submits\%20Comments\%20to\%20CMS\%20 on\%20Modernizing\%20Part\%20D\%20and\%20Medicare\%20Advantage\%20 to\%20Lower\%20Drug\%20Prices\%20and\%20Reduce\%20Out-of-Pocket $\% 20$ Expenses\%20proposed\%20rulemaking.pdf. Accessed July 28, 2020.

4. Prescription Drug Pricing Reduction Act of 2019 (H.R. 3/S. 2543). Available at: https://www.congress.gov/bill/116th-congress/senate-bill/2543?q=\%7B\%22 search $\% 22 \% 3 \mathrm{~A} \% 5 \mathrm{~B} \% 22 \% 5 \mathrm{C} \% 22$ Prescription+Drug+Pricing+Reduction+Act+o $\mathrm{f}+2019 \% 5 \mathrm{C} \% 22 \% 22 \% 5 \mathrm{D} \% 7 \mathrm{D} \& \mathrm{~s}=2 \& \mathrm{r}=1$. Accessed July 28, 2020. 